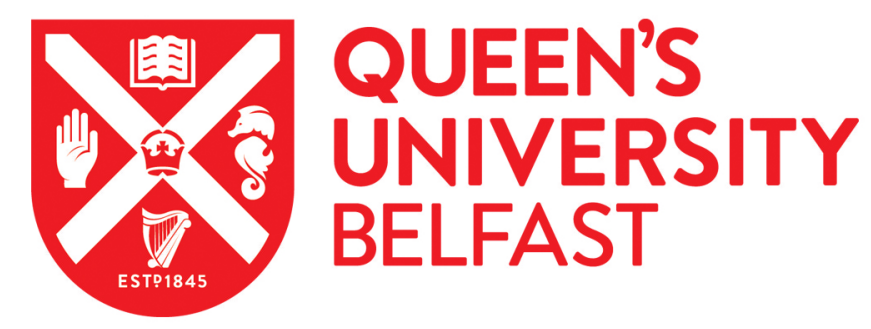

\title{
Activated lignin-chitosan extruded blends for efficient adsorption of methylene blue
}

\author{
Albadarin, A. B., Collins, M. N., Naushad, M., Shirazian, S., Walker, G., \& Mangwandi, C. (2016). Activated \\ lignin-chitosan extruded blends for efficient adsorption of methylene blue. Chemical Engineering Journal, \\ 307(1), 264. https://doi.org/10.1016/j.cej.2016.08.089
}

Published in:

Chemical Engineering Journal

Document Version:

Peer reviewed version

Queen's University Belfast - Research Portal:

Link to publication record in Queen's University Belfast Research Portal

Publisher rights

(c) 2016 Elsevier Ltd. This manuscript version is made available under the CC-BY-NC-ND 4.0 license http://creativecommons.org/licenses/by$\mathrm{nc}-\mathrm{nd} / 4.0 /$ which permits distribution and reproduction for non-commercial purposes, provided the author and source are cited.

\section{General rights}

Copyright for the publications made accessible via the Queen's University Belfast Research Portal is retained by the author(s) and / or other copyright owners and it is a condition of accessing these publications that users recognise and abide by the legal requirements associated with these rights.

Take down policy

The Research Portal is Queen's institutional repository that provides access to Queen's research output. Every effort has been made to ensure that content in the Research Portal does not infringe any person's rights, or applicable UK laws. If you discover content in the Research Portal that you believe breaches copyright or violates any law, please contact openaccess@qub.ac.uk. 


\section{Activated lignin-chitosan extruded blends for efficient adsorption of methylene blue}

Ahmad B. Albadarin ${ }^{1,2 *}$, Maurice N. Collins ${ }^{3}$, Mu Naushad ${ }^{4}$

Saeed Shirazian ${ }^{1}$,Gavin Walker ${ }^{1,2}$, C. Mangwandi ${ }^{2}$

${ }^{1}$ Department of Chemical and Environmental Sciences, Bernal institute, University of Limerick, Limerick, Ireland ${ }^{2}$ School of Chemistry and Chemical Engineering, Queen's University Belfast, Belfast BT9 5AG, Northern Ireland, UK

${ }^{3}$ Stokes Laboratories, Bernal Institute, University of Limerick, Ireland ${ }^{4}$ Department of Chemistry, College of Science, King Saud University, Riyadh-11451, Saudi Arabia

\section{Abstract}

This work investigates the production of activated lignin-chitosan extruded (ALiCE) pellets with controlled particle size distribution (almost spherical: dp 500-1000 $\mu \mathrm{m}$ ) for efficient methylene blue adsorption. The novel preparation method employed in this study successfully produced activated lignin-chitosan pellets. Structural and morphological characterizations were performed using BET, FTIR and SEM-EDX analyses. The influence of contact time, solution $\mathrm{pH}$, ionic strength, initial adsorbate concentration and desorption studies was investigated. The experimental data fitted well with the Langmuir isotherm $\left(R^{2}=0.997\right)$, yielding a maximum adsorption capacity of $36.25 \mathrm{mg} / \mathrm{g}$. The kinetic data indicated that methylene blue (MB) adsorption onto ALiCE can be represented by the pseudo second-order-model with intraparticle processes initially controlling the process of MB adsorption. Overall, these results indicate that the novel ALiCE offers great potential for removing cationic organic pollutants from rivers and streams.

Keywords: Adsorption; Lignin; Chitosan; Dyes; Blends Extrusion; Activated Carbon.

*Corresponding author: Dr Ahmad B. Albadarin: Ahmad.B.Albadarin@ul.ie.Tel: +353 (0) 61 237732; fax: +353 (0) 61202568. 


\section{Introduction}

2 The elimination of organic dyes from rivers and streams is a key environmental challenge [1].

3 Adsorption processes offer a mechanism for the removal and recovery of metals, dyes, oils, 4 organic mixtures and pharmaceuticals from water [2, 3]. The advantages of liquid phase 5 adsorption include: low cost, simplicity of design and operation [4], absence of sludge and 6 harmful by-product formation. This has been acknowledged by the United States 7 Environmental Protection Agency (USEPA) by classifying adsorption as one of the top control

8 methods [5]. Adsorption rates and adsorption quantities are two of the most significant 9 performance indices of any adsorption system. Hence, it is essential to design and prepare efficient adsorbents which are able to remove large amount of pollutants quickly using small amounts of adsorbent. Various adsorbent materials have been tested for the effective removal of dye such as methylene blue (MB) include spent olive stone [6] and raw dolomite [2]. Table 1 provides a comparison of the adsorption capacities of various adsorbents for the removal of MB dye [7-11]. Methylene blue has been explored in various medical applications including antimicrobial chemotherapy, biomedical dyes for cell staining, phototherapy and cancer research. Compared to other toxic materials and dyes, MB is not a particularly hazardous compound, though, large doses of $\mathrm{MB}(>7.0 \mathrm{mg} / \mathrm{kg})$ can cause high blood pressure, mental disorder, nausea, abdominal pain, etc. [12]. Also, MB can be freely photo-sensibilized by white light producing very reactive singlet species i.e. oxygen $\left({ }^{1} \mathrm{O}_{2}\right)$. These singlet oxygens can cause destruction to the DNA structures, especially at high concentrations and, ultimately, spread to the food chain. Pure lignin and chitosan have been employed individually and blended to remove dyes from aqueous solutions. Chitosan is a biopolymer with many advantages: nontoxicity, biocompatibility and biodegradability that can be obtained from the N-deacetylation

24 of chitin. However, chitosan is expensive, chemically unstable and can easily agglomerate .

25 Lignin is an amorphous aromatic polymer with complex structure formed by phenylpropane 
1 units. Lignin is well known as a cheap waste by-product from paper and wood mills. The

2 structural units of lignin vary depending on the source of biomass from which lignin is

3 extracted. The development of bio-composites and blends containing chitosan and lignin by-

4 product as adsorption materials will decrease the total cost of the adsorbent due to decrease in

5 the usage of costly chitosan, and offer a chance for exploiting the renewable by-products

6 produced in industries. Generally, composite/blended adsorption materials are prepared by

7 using many organic solvents, acid/basic and ionic solutions.

8 This paper investigates the development of a novel adsorbent, activated lignin-chitosan

9 extruded (ALiCE) pellets, for dye adsorption. In this study, the preparation method used very

10 few solvents and was easily operated in a continuous mode (extrusion). Also, the produced

11 material had a targeted particle size, effectively attracted the methylene blue dye with high

12 adsorption capacity and exhibited superior physical and chemical stabilities. A targeted particle

13 size means that the adsorbent can be explicitly manufactured to suit specific applications of

14 water treatment; pilot plant packed columns. The lignin-chitosan materials were blended and

15 extruded with acetic acid before thermal activation under $\mathrm{N}_{2}$ gas to enhance the mechanical and

16 physicochemical properties of the extrudates. Then, the application of the prepared activated

17 lignin-chitosan extrudates (ALiCE), as an adsorption material for methylene blue, was

18 investigated. The influence of experimental conditions such as contact time, initial $\mathrm{pH}$, ionic

19 strength and dye concentration on the adsorption were elucidated and the adsorption kinetics

20 were calculated to establish the efficiency of these novel materials.

212 . Material and procedure

22 Lignin (Alkali low sulfonate content), chitosan (95\% deacetylated), methylene blue

$23\left(\mathrm{C}_{16} \mathrm{H}_{18} \mathrm{ClN} \mathrm{N}_{3} \mathrm{~S}\right.$ : MW $\left.319.85 \mathrm{~g} / \mathrm{mol}\right)$ and acetic acid $\geq 99 \%$ were obtained from Sigma-Aldrich,

24 UK. Deionized water (resistivity $18.24 \Omega \cdot \mathrm{cm}$ ) was used to prepare synthetic dye solutions. 
2 A Caleva mini mixer (Multi Lab: serial number 800106) with a $30 \mathrm{~cm}^{3}$ stainless steel bowl,

3 within which are two contra-rotating blades with a $0-100 \mathrm{rpm}$ rotational speed, was used to 4 prepare the lignin-chitosan blends. An accurately weighed $20 \mathrm{~g}$ of lignin and chitosan (10g of 5 each) was mixed for 3min at 60rpm to obtain a uniform powdered mixture. Then, the mixture 6 was further granulated with $20 \mathrm{~cm}^{3}$ of aqueous acetic acid $(10 \% \mathrm{v} / \mathrm{v})$ solution for $10 \mathrm{~min}$ at 7 60rpm, followed by extruding the wet mass at 60rpm using a Caleva single extruder (MSE: 8 serial number 1037) fitted with a round-shaped screen (8 holes: perforation diameter: 1mm \& 9 thickness $=0.2 \mathrm{~mm}$ ). The extrudates were then spheronised for 5 mins in a Caleva spheroniser 10 (MBS: serial number 251101) containing a friction plate with cross-hatched geometry to 11 produce pellets with a size range of $\sim 500-1000 \mu \mathrm{m}$. Finally, the wet pellets were dried overnight at $80^{\circ} \mathrm{C}$, followed by activation in a three zone tabular furnace (TZF 12/65/550) under nitrogen atmosphere. Activation conditions were as follows: material mass =5g; 2 hours @ 200,400 and $600^{\circ} \mathrm{C}$ (ramp rate of $20^{\circ} \mathrm{C} / \mathrm{min}$ ); $\mathrm{N}_{2}$ at a flow rate of $56 \mathrm{~cm}^{3} / \mathrm{min}$. The activated lignin-chitosan extruded (ALiCE) material was finally rinsed with deionized water after which it was dried at $80^{\circ} \mathrm{C}$ for 12 hours before use.

\subsection{Characterisation of ALiCE adsorbent}

The surface area of the ALiCE was calculated from $\mathrm{N}_{2}$ adsorption measurements completed at liquid $\mathrm{N}_{2}$ temperature, $77 \mathrm{~K}$, using the Brunauer, Emmett and Teller (BET) equation. Fourier transform infrared spectroscopy (FT-IR), energy dispersive X-ray analysis (EDX) and scanning electron microscopy (SEM) were employed to examine the surface characteristics before and after adsorption using a Perkin Elmer Spectrum 100 within the range of $400-4000 \mathrm{~cm}^{-1}$ and JEOL-JSM 6400 scanning microscope, respectively. The zeta potential measurements were carried out using a Malvern zetasizer. The oxygenated acidic and basic surface groups were determined using the Boehm's titration method [13]. Single pellet diametric compression 
1 measurements were performed using a TA.XT2i Texture analyser materials testing machine

2 with a PC for real time data logging and analysis.

\subsection{Batch studies}

All the experiments were performed with artificial wastewater stock solution of $1000 \mathrm{mg} / \mathrm{dm}^{3}$ prepared by dissolving a precise amount of methylene blue in deionized water. Experiments were performed by mixing $0.05 \mathrm{~g}$ of ALiCE adsorbent with $25 \mathrm{~cm}^{3}$ of MB solutions in a $50 \mathrm{~cm}^{3}$ screw type glass jar at room temperature $\left(\sim 20^{\circ} \mathrm{C}\right)$. The $\mathrm{pH}$ of $\mathrm{MB}$ solutions is obtained using a pH meter (Orion 3-Star). Good contact is made between ALiCE adsorbent and MB solutions by agitating at 110rpm on a mechanical shaker (Gerhardt type LS5). The MB adsorption was investigated at $\mathrm{pH}(2-9)$ with $C_{0}$ of $43.65 \mathrm{mg} / \mathrm{dm}^{3}$ and dosage $2.0 \mathrm{~g} / \mathrm{dm}^{3}$, initial $\mathrm{MB}$ concentrations $\left(10.15-82.01 \mathrm{mg} / \mathrm{dm}^{3}\right)$. After equilibrium, the adsorbent was isolated from the MB solution by centrifugation at 5000rpm for $5 \mathrm{~min}$. MB concentrations were obtained spectrophotometrically by detecting the absorbance at $\lambda_{\max }=664 \mathrm{~nm}$ using a Perkin Elmer LAMBDA 25, UK. For the contact time experiments at different MB concentrations, 10.15$82.01 \mathrm{mg} / \mathrm{dm}^{3}$, the same conditions were applied (optimal $\mathrm{pH}=7$ and room temperature $\sim 20^{\circ} \mathrm{C}$ ), and the solution volume used was $250 \mathrm{~cm}^{3}$. The $q_{\mathrm{e}}$ values obtained from the contact time experiment were used to construct the $q_{\mathrm{e}} \mathrm{vs} C_{\mathrm{e}}$ plots and the isotherm analysis at $20^{\circ} \mathrm{C}$. In order to study the effect of ionic strength: $\mathrm{LiCl}, \mathrm{KCl}$ and $\mathrm{NaCl}$ salts were added to $\mathrm{MB}$ solutions at $\mathrm{pH}=7, C_{\mathrm{o}}=43.65 \mathrm{mg} / \mathrm{dm}^{3}$ and $20^{\circ} \mathrm{C}$. Adsorption experiments were performed in duplicate and average values were reported. The standard error was less than 5\%. Desorption experiments were carried out in order to investigate the regeneration of the adsorbent and evaluate the mechanism involved in MB adsorption. The loaded ALiCE sample from the $\mathrm{pH}$ experiment $(\mathrm{pH}=7)$ was used for the desorption study. Loaded ALiCE was immersed in $25 \mathrm{~cm}^{3}$ of desorbent solutions: $0.11 \mathrm{M} \mathrm{HCl}$, deionised water and $0.1 \mathrm{M} \mathrm{NaOH}$ and the suspensions were shaken for $12 \mathrm{~h}$. After that, the ALiCE material was separated and the amount of MB desorbed 
1 was computed. Finally, it is worth mentioning that after adsorption-desorption process, the

2 adsorbent pellets remained intact.

\subsection{Theory of adsorption, isotherms and kinetics}

4 Methylene blue uptake, $q$ (mg/g), and percentage of removal (\%) were obtained according to

$5 \quad$ Eq. (1) and (2), respectively:

$6 q=\left[\frac{C_{o}-C_{e}}{M}\right] \times V$

7 The percentage removal $=\left[1-\frac{C_{e}}{C_{o}}\right] \times 100 \%$

8 where $C_{\mathrm{o}}$ is the initial and $C_{\mathrm{e}}$ is the equilibrium concentration of methylene blue (MB) in $\mathrm{mg} /$

$9 \mathrm{dm}^{3}, M$ is the amount of adsorbent in grams and $V$ is the volume of the MB solution in $\mathrm{dm}^{3}$.

10 The Lagergren's pseudo-first and second-order [14, 15] and intraparticle diffusion [16] models

11 were used to describe the kinetic data tested:

$12 \quad q_{t}=q_{e}\left(1-e^{-k_{1} t}\right)$

$13 \quad q_{t}=\frac{k_{2} q_{e}^{2}}{\left(1+k_{2} q_{e} t\right)} t$

$14 \quad q_{t}=k_{i d} \times t^{1 / 2}+C$

15 where $k_{1}(1 / \mathrm{min})$ and $k_{2}$ (g/mg min) are the pseudo-first-order and the pseudo-second-order rate

16 constants, respectively. $k_{\mathrm{id}}$ is the intraparticle diffusion rate constant $\left(\mathrm{mg} /\left(\mathrm{g} \mathrm{min}^{1 / 2}\right)\right)$ and $C$ the

17 intercept related to the boundary layer effect. The adsorption initial rates were calculated from

18 pseudo-first and second-order models by using the equations:

$19 \quad h_{0,1}=k_{1} \times q_{e}$

$20 \quad h_{0,2}=k_{2} \times q_{e}{ }^{2}$ 
1 The isotherm adsorption data was represented by a number of isotherm equations namely:

2 Langmuir [17], Freundlich [18], Redlich-Peterson [19] and Sips [20] adsorption isotherm

3 models:

$4 \quad$ Langmuir isotherm: $q_{e}=q_{\max }\left[\frac{b C_{e}}{1+b C_{e}}\right]$

5 Freundlich isotherm: $q_{e}=K_{F} C_{e}^{1 / n}$

$6 \quad$ Redlich-Peterson isotherm: $q_{e}=\frac{K_{R} C_{e}}{1+a_{R} C_{e}^{\beta}}$

7 Sips isotherm: $q_{e}=q_{\max }\left[\frac{K_{s} C_{e}^{n_{s}}}{1+K_{s} C_{e}^{n_{s}}}\right]$

8 where $q_{\max }(\mathrm{mg} / \mathrm{g})$ and $b\left(\mathrm{dm}^{3} / \mathrm{mg}\right)$ are the Langmuir isotherm constants; $K_{\mathrm{F}}\left(\mathrm{mg} / \mathrm{g}\left(\mathrm{dm}^{3} / \mathrm{mg}\right)^{1 / \mathrm{n}}\right)$

9 and $1 / \mathrm{n}$ are related to the adsorption capacity of the adsorbent and adsorption intensity,

10 respectively; $K_{\mathrm{R}}\left(\mathrm{dm}^{3} / \mathrm{g}\right), a_{\mathrm{R}}$ and $\beta$ are the Redlich-Peterson isotherm constants, where: $0 \leq \beta \leq$

11 1. The Sips isotherm: $K_{\mathrm{s}}\left(\mathrm{dm}^{3} / \mathrm{mmol}\right)$ is associated with the energy of adsorption and $n_{\mathrm{s}}$ indicates

12 the system heterogeneity.

13 The fundamental characteristics of Langmuir isotherm, defined by Webber and Chakkravorti

14 [21], can be expressed by a dimensionless constant called separation factor, $R_{\mathrm{L}}$ :

$15 \quad R_{L}=\frac{1}{1+b C_{o}}$

$16 R_{\mathrm{L}}$ indicates the shape of isotherm as follows: and $R_{\mathrm{L}}=0$ (irreversible); $R_{\mathrm{L}}>1$ (unfavourable);

$17 \quad R_{\mathrm{L}}=1$ (linear); $0<R_{\mathrm{L}}<1$ (favourable).

\section{Results and discussion}

\subsection{ALiCE characteristics}

20 One of the main objectives of this study is to prepare activated carbon with targeted size and high mechanical strength. The final ALiCE pellets were semi spherical with diameters from 
$1400-800 \mu \mathrm{m}$ and approx. $1 \mathrm{~mm}$ long. The char yields after 200,400 and $600^{\circ} \mathrm{C}$ carbonization were 67.7, 61.3 and $56.4 \mathrm{wt} \%$, respectively. However, the prepared ALiCE adsorbent particles at $600^{\circ} \mathrm{C}$ are the most robust with the highest mechanical strength and lowest dust content even in comparison to commercial activated carbon, AC (Filtrasorb FS-400). The calculated failure loads for the ALiCE at 200, 400, $600^{\circ} \mathrm{C}$ and for AC are 5.463, 7.332, 9.597 and $8.218 \mathrm{~N}$, respectively. Based on that, the $\mathrm{ALiCE}$ prepared at $600^{\circ} \mathrm{C}$ was used in the adsorption experiments. The specific surface area of ALiCE was calculated as $80.77 \mathrm{~m}^{2} / \mathrm{g}$, which is larger than that for chemically prepared lignin-chitosan blends $\left(2.44 \mathrm{~m}^{2} / \mathrm{g}\right)[22], \mathrm{pZ} 4$ activated sample $\left(25.19 \mathrm{~m}^{2} / \mathrm{g}\right)$ and smaller than pP6 activated sample $\left(1041.43 \mathrm{~m}^{2} / \mathrm{g}\right)$ prepared in [23]. Adsorbent surfaces could comprise chemical functional groups of acidic or basic nature. Such groups often have an effect on the adsorption process of pollutants in wastewater. The acidity and basicity of ALiCE surface values were calculated as: acidity $=0.279 \mathrm{mmol} / \mathrm{g}$ and basicity $=0.047$ $\mathrm{mmol} / \mathrm{g}$. It is obvious that the acidic characteristic of ALiCE is higher than its basic characteristic. It is known that, carbons with high oxygen content show acidic surface properties and cation exchange behaviour.

\subsection{Effect of solution pH and ionic strength}

The adsorption removal capacity depends on the adsorbent surface properties and adsorbate structure which are greatly affected by $\mathrm{pH}$. The measurements of zeta potential and influence of the $\mathrm{pH}$ solution value on adsorption of the MB was investigated and the results are illustrated in Figure 1. At natural pH, the zeta potential measured for ALiCE adsorbent is approx. $-20 \mathrm{mV}$. This value indicates that ALiCE surface is negatively charged. Starting from the ALiCE natural $\mathrm{pH}$, altering the $\mathrm{pH}$ of $\mathrm{MB}$ solutions indicates the difference of the zeta potential against the $\mathrm{pH}$ of the aqueous phase in the range 2-9. The MB removal efficiency increases slightly with an increase with the $\mathrm{pH}$ value from 2 to 4, and then the efficiency to some extent rises when the $\mathrm{pH}$ elevated from 4 to 7 . The maximum adsorption percentage removal was $87.69 \%$ at $\mathrm{pH}$ 
1 7. Additional increase in the $\mathrm{pH}$ beyond 7 consequences in a small reduction in the removal

2 effectiveness. At high $\mathrm{pH}$ values, the presence of high concentrations of $\mathrm{OH}$-ions increases the

3 negative charge on the ALiCE surface by deprotonating the positively charged sites. These

4 phenomena are attributed to the value of the measured zeta potential. The negative charge value

5 was sharply enhanced when the initial solution $\mathrm{pH}$ was increased from 5 to 7 . At $\mathrm{pH}$ values >

6 7, the ALiCE surface has more anionic charges, and the surface would participate in cation

7 attraction and cation exchange reactions. Thus, the barrier to dye molecules diffusion decreases

8 and results in a high adsorption capacity due to the significantly high electrostatic attraction

9 which occurs between the positive dye molecules and the negatively charged ALiCE surface.

10 Finally, at low $\mathrm{pH}$, while the ALiCE less negative surface does not favour the adsorption

11 process as a result of the electrostatic repulsion, a substantial amount of dye adsorption onto

12 ALiCE still takes place at low $\mathrm{pH}$ values. This indicates that other mechanisms other than electrostatic attraction are operative for the MB adsorption onto ALiCE. The effect of ionic strength was investigated by adding $\mathrm{LiCl}, \mathrm{KCl}$ and $\mathrm{NaCl}$ salts to the $\mathrm{MB}$ solutions. It was found that the cations can change the surface property of ALiCE in the order $\mathrm{K}^{+}>\mathrm{Na}^{+}>\mathrm{Li}^{+}$. The adsorption efficiency slightly decreased from 87.69 to $81.12,83.42$ and 84.07 due to the addition of $\mathrm{K}^{+}, \mathrm{Na}^{+}, \mathrm{Li}^{+}$, respectively. The hydrated radius of $\mathrm{K}^{+}=2.32 \AA$ which is smaller than $\mathrm{Na}^{+}=2.76 \AA$ and $\mathrm{Li}^{+}=3.4 \AA$. This explains the stronger competition between $\mathrm{MB}^{+}$and $\mathrm{K}^{+}$and as a results the more obvious influence on MB adsorption compared with the other two cations. However, the small reduction in the MB adsorption efficiency indicates the selective adsorption of ALiCE for MB. Similar trends have been reported for Adsorption of methylene blue onto multiparous palygorskite modified by ion beam bombardment [24].

\subsection{Effect of contact time and initial concentration}

24 The effect of exposure time on the performance of ALiCE in adsorbing MB was investigated 
1 uptake values increased from 4.60 to $27.90 \mathrm{mg} / \mathrm{g}$, due to the increase in the driving force from

2 the concentration gradient. The adsorption process was fast in the initial phase $\sim 150 \mathrm{~min}$ and

3 the adsorption capacities increased quickly. Subsequently the adsorption of MB sustained at a

4 slower rate until the adsorption rate attained a constant value at its maximum level after approx.

$540 \mathrm{~h}$ of reaction; maximum levels were found for all concentrations as shown in Figure 2.

6 The fast initial adsorption rates are attributed to the high number of accessible free functional 7 groups e.g. $-\mathrm{OH}$ and $-\mathrm{NH}_{2}$ on the surface of the ALiCE adsorbent at the start of the adsorption

8 process and less steric hindrance for the approaching dye molecules. The slow adsorption

9 process is a result of the reduction in the available adsorption positions and the build-up of MB

10 molecules on the surface of the ALiCE adsorbent; this hinders the diffusion of more MB

11 molecules into the ALiCE pores. Slow diffusion rates are related to pores which are of a similar

12 size to the diffusing molecules [25]. Furthermore, in order to demonstrate how near the

13 processes at any time are to equilibrium, the values of the fractional uptake $f\left(q_{t} / q_{\mathrm{e}}\right)$ were plotted

14 against time $t$ (Figure 2B). Figure 2B illustrates that the fractional uptakes $f$ decrease and the

15 time necessary to achieve equilibrium increases with increased initial MB concentrations.

$16 \quad 3.4$. Kinetic modelling

17 The kinetic results were fit to Eqs. (3) and (4) using SigmaPlot 11.0 nonlinear regression software; the fitting results and the values of the calculated constants are shown in Figure 2A 19 and Table 2, respectively.

20 It was found that $k_{1}$ and $k_{2}$ of the pseudo-first and second-order rate constants decrease with an 21 increase in the MB concentration $\left(C_{0}\right)$ values. This is attributed to competition between higher 22 levels of MB molecules for the adsorbent active sites. The tendency that $k_{1}$ declines with 23 increasing $C_{0}$ suggests that it is quicker for a system with a lower $C_{0}$ to attain a definite 24 fractional uptake. This phenomenon is supported by the trends in plots in Figure 2B. From 25 Figure 2A, the first-order equation of Lagergren has described the kinetic data over the early 
1 stage of the adsorption processes only, especially at high MB concentrations but not over the

2 enter contact time. Conversely, kinetics of the adsorption of MB onto ALiCE best fit the

3 pseudo-second-order model for the whole contact time range with correlation coefficient, $R^{2}$,

4 values close to unity and agreeing well with calculated adsorption capacities, $q_{\mathrm{e}}$, with the

5 experimental data $q_{\text {exp. }}$ This indicates that the adsorption mechanism depends on the adsorbent

6 and adsorbate, and the chemisorption is the rate-controlling step containing valence forces

7 through the exchange/sharing of electrons . The calculated values of $h_{0,1}, h_{0,2}$ as well as the rate

8 constant of external mass transfer, $k_{s}$, at the start of adsorption (determined from the plots of

$9 C_{t} / C_{0}$ against time at various $C_{0}$ values (plots are not shown here)) are revealed in Figure 3.

10 The overall trend observed in Figure 3 is a decline in the initial rates of adsorption with increase

11 in the initial MB concentrations. The decrease of $k_{\mathrm{s}}$ with increasing $C_{\mathrm{o}}$ was previously reported

12 for dye adsorption and as before is attributed to the MB dye molecules competing for accessible surface area. This competition appears to have more impact on the adsorption initial rates than the increasing driving force caused by higher dye concentration. Also, it was observed that the estimation of the adsorption initial rate by $k_{\mathrm{s}}$ is more consistent than $h_{0,1}$ and $h_{0,2}$. This is due to (i) $k_{\mathrm{s}}$ is calculated without any hypothetical assumptions regarding the adsorption mechanism: it is obtained directly from the temporal change of $C_{\mathrm{t}} / C_{\mathrm{o}}$; (ii) $k_{\mathrm{s}}$ is accurately calculated at $t=$ 0, from fitting $C_{t} / C_{o}$ values for a short time at the start of adsorption, whereas $h_{0,1}$ and $h_{0,2}$ are calculated from estimates of $q_{\mathrm{e}}$ and $k$ throughout the entire adsorption period.

\subsection{Diffusion parameters}

21 The entire process of adsorption can be divided into four major steps: (i) dye molecules travel from the bulk solution to the adsorbent surface by bulk diffusion. The transport of dye molecules through the boundary occurs due to random molecular motion of individual molecules [26]; (ii) film diffusion; (iii) intra-particle or pore diffusion of the dye (iv) chemical reaction or complex formation [27]. The plots of the intraparticle diffusion (Eq. 5) display 
1 multi-linearity, demonstrating three stages which are taking place, related to steps (ii), (iii) and

2 (iv) (Figure 4A). Stage (i) occurs too quickly to be observed. The time needed for the second

3 step is typically related to the changes in the system (i.e. temperature, adsorbent particle size

4 and solute concentration, and), which make it complicated for prediction or control [28]. The

5 calculated $k_{\text {id }}$ values are presented in Table 3. It can be seen that the rate constants for

6 intraparticle diffusion increased with increasing $\mathrm{MB}$ initial concentrations which are

7 attributable to the greater driving force at higher $C_{0}$ values. At the beginning of the diffusion

8 process (short times), Fick’s law reduces to Equation 13 [29, 30]:

$9 \quad \frac{q_{t}}{q_{e}}=6\left(\frac{D_{1}}{\pi r^{2}}\right)^{0.5} t^{0.5}$

where $D_{1}$ is the film diffusion and $r$ is the radius of the ALiCE particle.

11 For longer times, the relationship between weight uptake and diffusion can be described by the 12 approximated Boyd model [31]:

$13 \quad B t=-0.4977-\ln (1-F)$

(14), $\quad$ where $\mathrm{F}=q_{\mathrm{t}} / q_{\mathrm{e}}$,

14 The intraparticle (pore) diffusion, $D_{2}\left(\mathrm{~cm}^{2} / \mathrm{s}\right)$, can be determined by plotting $\mathrm{B} t$ against time;

15 from the equation: Slope $=B=\pi^{2} D_{2} / r^{2}$

16 The rate of mass transfer is controlled by pore diffusion if the plots of Bt $v s t$ at different MB

17 concentrations linearly pass via the origin. If the plots are either linear or nonlinear and do not

18 pass through the origin, the adsorption rate is ruled by chemical reaction or film diffusion [32].

19 From Figure 4B, it can be confirmed that the adsorption rate is not limited by pore diffusion

20 during the initial period as the plots do not pass through the origin and that film diffusion or 21 chemical reaction limits the rate of adsorption through this early stage [32]. However, for longer

22 MB adsorption times pore diffusion is the controlling process. Results show that the film and

23 pore diffusion decreased as the initial MB concentration increased. The decrease in $D_{1}$ and $D_{2}$

24 with increasing MB concentration is attributed to a reduction in the number of available open 
1 sites for adsorption with increasing initial concentration. The results also show that the film

2 diffusion is faster than the pore diffusion. Diffusion coefficients in the order of $10^{-6}$ to $10^{-8}$ are

3 found when the rate is governed by film diffusion whereas the diffusion coefficients are in the

4 order of $10^{-11}$ to $10^{-13}$ when the rate is controlled by pore diffusion [33]. Based on the diffusion

5 coefficients magnitudes in Table 3, both film and intraparticle (pore) processes are initially

6 involved in the MB adsorption process and that pore diffusion is the sole controlling process

7 over longer periods.

\subsection{Equilibrium isotherms}

9 The equilibrium data was tested by Langmuir, Freundlich, Redlich-Peterson and Sips 10 isotherms and the plots are illustrated in Figure 5A. The isotherms constants are shown in 11 Table 4. As can be observed from Figure 5A and Table 4, apart from the Freundlich isotherm equilibrium, the equilibrium data fitted well to all isotherm models with a correlating constant $\left(R^{2}\right)$ higher than 0.99 . The good fit of experimental equilibrium data of the adsorption of $\mathrm{MB}$ onto ALiCE to the Langmuir isotherm indicates the chemisorption and monolayer adsorption onto the ALiCE surface where adsorption sites are identical with similar affinities. The maximum adsorption capacities calculated by Langmuir and Sips were very similar and relatively high. High adsorption capacity is expected due to the relatively high surface area of ALiCE. The Redlich-Peterson constant, $\beta$, was close to unity (0.965), demonstrating that the isotherm can be reduced the Langmuir isotherm form [6]. Also, the values of $1 / n$ were higher than unity implying that the adsorption process is chemical. The $R_{\mathrm{L}}$ values are shown in Figure 5B (0.448 to 0.091) and suggest that the adsorption of MB onto ALiCE is a favourable one, and at high $C_{0}$ values, the adsorption is nearly irreversible. Finally, the surface area of the ALiCE was calculated using MB adsorption capacity $\left(q_{\max }\right)$ and compared to that obtained by the BET method ( $\mathrm{N}_{2}$ adsorption in gaseous phase). Assuming a complete adsorption of $\mathrm{MB}$ as a monolayer on the ALiCE surface, the surface area can be calculated by: 
1 Surface area $\left(\mathrm{m}^{2} / \mathrm{g}\right)=\frac{q_{\max } \times A_{M B} \times N_{L} \times 10^{-3}}{M W}$

2 where $A_{M B}$ is the surface area taken by one molecule of $\mathrm{MB}=130 \AA^{2}, N_{\mathrm{L}}$ is the Avogadro's

3 number $=6.023 \times 10^{23}$ molecule $/$ mole and $M W$ is the molecular weight of $\mathrm{MB}=320 \mathrm{~g} / \mathrm{mol}$.

4 The surface area of the ALiCE by MB adsorption was $88.69 \mathrm{~m}^{2} / \mathrm{g}$. This value is close to that 5 obtained by the BET method $\left(80.77 \mathrm{~m}^{2} / \mathrm{g}\right)$. The slightly higher surface area accessed using the $6 \mathrm{MB}$ adsorption method is attributed to the MB aggregation and the instrumental theory of a 7 cylindrical pore volumes which is not necessarily the case [34].

\subsection{Desorption studies}

9 The MB-loaded-ALiCE was eluted using $\mathrm{HCl}$, deionized water and $\mathrm{NaOH}$, and the amount of MB desorbed (\%desorption) was determined using the following relationship:

11 Desorption $(\%)=\frac{C_{\text {des }}}{C_{\text {ads }}} \times 100$

12 where $C_{\text {des }}$ is the concentration of dye in desorbed and $C_{\text {ads }}\left(\mathrm{mg} / \mathrm{dm}^{3}\right)$ is the concentration at 13 adsorbed phases.

14 The amount of MB desorbed was relatively low with the maximum MB desorbed percentage 15 was $13.4 \%$ and it was obtained for strong acidic conditions $(0.1 \mathrm{M} \mathrm{HCl})$. For higher $\mathrm{pH}$ values $16(\mathrm{NaOH})$ and deionized water, the desorption was very low and limited to $4-7 \%$. The low desorption of MB by an acidic medium shows that the MB molecules were mainly adsorbed onto the ALiCE through strong chemisorption mechanisms. The results indicate that the regeneration of ALiCE by using acid or alkaline solutions is not feasible. However, the reduced colour leachability from the dye-loaded ALiCE is a good property bearing in mind the disposal

21 in landfill or reuse for other purposes for instance: in polymeric composites or incorporation in construction materials. 
2 The FT-IR spectra in Figure 6 shows structural changes in the ALiCE adsorbents after MB

3 adsorption, confirmed by the changes of functional group bands due to the dye adsorption. The

4 absorption peak around $34351 / \mathrm{cm}$ is due to stretching of phenolic and aliphatic $-\mathrm{OH}$ and $-\mathrm{N}$

$5 \quad \mathrm{H}$ groups. The peaks at 2918 and 2850 1/cm correspond to $\mathrm{C}-\mathrm{H}$ and $-\mathrm{CH}_{2}-$ stretching modes.

6 The peak at $16261 / \mathrm{cm}$ is due to bending of -NH in primary amine group. Symmetric bending

7 of $-\mathrm{O}-\mathrm{CH}_{3}$ is detected at $14581 / \mathrm{cm}$. The peaks around $12001 / \mathrm{cm}$ are assigned to $\mathrm{C}-\mathrm{O}-\mathrm{C}$

8 stretching in $\alpha-\mathrm{O}-4$ and $\beta-\mathrm{O}-4$ linkages of alkali lignin [35]. The peak at $6711 / \mathrm{cm}$ is attributable

9 to the out-of-plane bending of the $\mathrm{O}-\mathrm{H}$ group. The changes in ALiCE surface characteristics

10 i.e. change in all peak heights and shifts of functional group bands after MB loading indicate

11 that groups for example hydroxyl and amine groups are involved in the adsorption process as

12 expected. The SEM images demonstrated noteworthy changes in surface topography between the raw extruded lignin-chitosan blends, the activated extrudates and MB-loaded ALiCE. This deviation in the surface morphology is due to the activation process which has changed the quantities of available functionalities and their interactions. The development of chitosan agglomerates on the lignin surface before activation is obvious at the surface of the blends. This is due to the interactions between $\beta$-1,4-glycosidic linkage, amide and hydroxyl groups of chitosan, and ether, aromatic ring and hydroxyl groups of alkali lignin. After activation, the ALiCE surface was flattened with large, irregular intercellular spaces and well-defined edges. This indicates that the lignin-chitosan blended structure was rearranged during and after the activation. The SEM image of the MB-loaded-ALiCE showed that the edges and intercellular spaces of the microstructure disappeared after the MB adsorption and the structure is more relaxed with a paste like texture. The EDX chemical analysis of the ALiCE indicated that the unloaded ALiCE contained approx. 3.5\% S and 5.7\% Na. The EDX of the MB-loaded ALiCE showed the non-appearance of $\mathrm{Na}$ and that no apparent changes in elemental composition took place, signifying that ion-exchange is involved in the MB binding mechanisms. The structure 
1 relaxation could be due to stripping of alkaline elements such as Na which is present in trace

2 quantities originating mainly from alkali lignin. The FT-IR and SEM analysis confirm that the

3 dye adsorption occurs possibly through electrostatic attractions/surface exchanges until the

4 functional sites are completely unavailable; subsequently, MB molecules diffuse into ALiCE

5 particles for more interactions possibly hydrophobic interactions and hydrogen bonding.

\section{4. Concluding remarks}

7 A new method involving extrusion and thermal activation was successfully employed in the

8 production of activated lignin-chitosan extruded (ALiCE) pellets. The ALiCE materials were synthesized, structurally characterized, and used in selective cationic dye (methylene blue (MB)) adsorption. The chemisorption dye adsorption mechanisms were revealed and it was concluded that electrostatic attractions and chemical interactions were observed between amino and hydroxyl groups of the ALiCE adsorbent and amine groups of the dye. Using the Langmuir isotherm a maximum adsorption capacity of $36.25 \mathrm{mg} / \mathrm{g}$ is calculated. The FTIR, electron microscopy and desorption studies confirmed that strong chemical bonds occurred between the MB molecules and the functional groups on the ALiCE.

Acknowledgement

The authors would like to thanks Mr James McClean from Queen’s University Belfast for his proofreading which has profoundly improved the quality of this article.

\section{References}

[1] S.K. Nataraj, K.M. Hosamani, T.M. Aminabhavi, Nanofiltration and reverse osmosis thin film composite membrane module for the removal of dye and salts from the simulated mixtures, Desalination 249 (2009) 12-17.

[2] A.B. Albadarin, J. Mo, Y. Glocheux, S. Allen, G. Walker, C. Mangwandi, Preliminary investigation of mixed adsorbents for the removal of copper and methylene blue from aqueous solutions, Chemical Engineering Journal 255 (2014) 525-534.

[3] T.M. Aminabhavi, P. Munk, Preferential Adsorption onto Polystyrene in Mixed Solvent Systems, Macromolecules 12 (1979) 607-613.

[4] Y. Salameh, A.B. Albadarin, S. Allen, G. Walker, M.N.M. Ahmad, Arsenic(III,V) adsorption onto charred dolomite: Charring optimization and batch studies, Chemical Engineering Journal 259 (2015) 663-671.

[5] M. Fayazi, M. Ghanei-Motlagh, M.A. Taher, The adsorption of basic dye (Alizarin red S) from aqueous solution onto activated carbon $/ \gamma$-Fe2O3 nano-composite: Kinetic and equilibrium studies, Materials Science in Semiconductor Processing 40 (2015) 35-43. 
[6] A.B. Albadarin, C. Mangwandi, Mechanisms of Alizarin Red S and Methylene blue biosorption onto olive stone by-product: Isotherm study in single and binary systems, Journal of Environmental Management 164 (2015) 86-93.

[7] S.K. Theydan, M.J. Ahmed, Adsorption of methylene blue onto biomass-based activated carbon by FeCl3 activation: Equilibrium, kinetics, and thermodynamic studies, Journal of Analytical and Applied Pyrolysis 97 (2012) 116-122.

[8] E.I. El-Shafey, S.N.F. Ali, S. Al-Busafi, H.A.J. Al-Lawati, Preparation and characterization of surface functionalized activated carbons from date palm leaflets and application for methylene blue removal, Journal of Environmental Chemical Engineering 4 (2016) 2713-2724.

[9] K.T. Wong, N.C. Eu, S. Ibrahim, H. Kim, Y. Yoon, M. Jang, Recyclable magnetite-loaded palm shell-waste based activated carbon for the effective removal of methylene blue from aqueous solution, Journal of Cleaner Production 115 (2016) 337-342.

[10] M. Ghaedi, M.D. Ghazanfarkhani, S. Khodadoust, N. Sohrabi, M. Oftade, Acceleration of methylene blue adsorption onto activated carbon prepared from dross licorice by ultrasonic: Equilibrium, kinetic and thermodynamic studies, Journal of Industrial and Engineering Chemistry 20 (2014) 2548-2560.

[11] O.S. Amuda, A.O. Olayiwola, A.O. Alade, A.G. Farombi, S.A. Adebisi, Adsorption of methylene blue from aqueous solution using steam activated carbon produced from lantana camara stem, Journal of Environmental Protection 5 (2014) 1352-1363

[12] M. Oz, D.E. Lorke, M. Hasan, G.A. Petroianu, Cellular and molecular actions of Methylene Blue in the nervous system, Medicinal Research Reviews 31 (2011) 93-117.

[13] J.J.M. Órfão, A.I.M. Silva, J.C.V. Pereira, S.A. Barata, I.M. Fonseca, P.C.C. Faria, M.F.R. Pereira, Adsorption of a reactive dye on chemically modified activated carbons-Influence of $\mathrm{pH}$, Journal of Colloid and Interface Science 296 (2006) 480-489.

[14] S. Lagergren, Zur theorie der sogenannten adsorption gelöster stoffe KungligaSvenska Vetenskapsakademiens, Handlingar 24 (1898) 1-39.

[15] Y.S. Ho, G. McKay, Pseudo-second order model for sorption process, Process Biochemistry 34 (1999) 451-465.

[16] W.J. Weber, J.C. Morris, Kinetics of Adsorption on Carbon from Solution, Journal of the Sanitary Engineering Division 89 (1963) 31-60.

[17] I. Langmuir, The constitution and fundamental properties of solids and liquids,, Journal of the American Chemical Society 38 (1916) 2221-2295.

[18] H.M.F. Freundlich, Over the adsorption in solution, Journal of Physical Chemistry 57 (1906) 385471.

[19] O. Redlich, D.L. Peterson, A useful adsorption isotherm, Journal of Physical Chemistry 63 (1959) 1024-1026.

[20] R. Sips, On the Structure of a Catalyst Surface, Journal of Chemical Physics 16 (1948) 490-495. [21] T.W. Webber, C. R.K., Pore and solid diffusion models for fixed-bed adsorbers, AlChE Journal 20 (1974) 228-238.

[22] V. Nair, A. Panigrahy, R. Vinu, Development of novel chitosan-lignin composites for adsorption of dyes and metal ions from wastewater, Chemical Engineering Journal 254 (2014) 491-502.

[23] A.C. Arampatzidou, E.A. Deliyanni, Comparison of activation media and pyrolysis temperature for activated carbons development by pyrolysis of potato peels for effective adsorption of endocrine disruptor bisphenol-A, Journal of Colloid and Interface Science 466 (2016) 101-112.

[24] J. Zhang, D. Cai, G. Zhang, C. Cai, C. Zhang, G. Qiu, K. Zheng, Z. Wu, Adsorption of methylene blue from aqueous solution onto multiporous palygorskite modified by ion beam bombardment: Effect of contact time, temperature, pH and ionic strength, Applied Clay Science 83-84 (2013) 137-143.

[25] A.B. Albadarin, C. Mangwandi, A.a.H. Al-Muhtaseb, G.M. Walker, S.J. Allen, M.N.M. Ahmad, Kinetic and thermodynamics of chromium ions adsorption onto low-cost dolomite adsorbent, Chemical Engineering Journal 179 (2012) 193-202.

[26] T.M. Aminabhavi, U.S. Aithal, S.S. Shukla, An Overview of the Theoretical Models Used to Predict Transport of Small Molecules through Polymer Membranes, Journal of Macromolecular Science, Part C 28 (1988) 421-474. 
[27] C. Mangwandi, A.B. Albadarin, Y. Glocheux, G.M. Walker, Removal of ortho-phosphate from aqueous solution by adsorption onto dolomite, Journal of Environmental Chemical Engineering 2 (2014) 1123-1130.

[28] F.-C. Wu, R.-L. Tseng, R.-S. Juang, Initial behavior of intraparticle diffusion model used in the description of adsorption kinetics, Chemical Engineering Journal 153 (2009) 1-8.

[29] J. Crank, The Mathematics of Diffusion, Second ed. Clarendon Press, Oxford (1975).

[30] U.S. Aithal, T.M. Aminabhavi, Measurement of diffusivity of organic liquids through polymer membranes: A simple and inexpensive laboratory experiment, Journal of Chemical Education 67 (1990) 82.

10 [31] D. Reichenberg, Properties of ion exchange resins in relation to their structure. III. Kinetics of 11 exchange, Journal of the American Chemical Society 75 (1953) 589-598. [32] A.B. Albadarin, C. Mangwandi, G.M. Walker, S.J. Allen, M.N. Ahmad, Biosorption characteristics of sawdust for the removal of Cd(II) Ions: Mechanism and thermodynamic studies, Chemical Engineering Transactions (2011) 1297-1302. [33] L.D. Michelson, ., P.G. Gideon, E.G. Pace, L.H. Kutal, Removal of soluble mercury from wastewater by complexing techniques, US Department of Industry; Office of Water Research and Technology Bulletin, Washington DC, 1975.

[34] E.A. Ustinov, D.D. Do, M. Jaroniec, Adsorption of argon and nitrogen in cylindrical pores of MCM-41 materials: application of density functional theory, Applied Surface Science 252 (2005) 10131028.

[35] Z. Ma, Q. Sun, J. Ye, QiufangYao, C. Zhao, Study on the thermal degradation behaviors and kinetics of alkali lignin for production of phenolic-rich bio-oil using TGA-FTIR and Py-GC/MS, Journal of Analytical and Applied Pyrolysis 117 (2016) 116-124.

24 
1 Table 1: Comparison of various adsorbents: sorption capacity for MB adsorption.

\begin{tabular}{|c|c|c|c|}
\hline Adsorbent & $\begin{array}{l}\text { Adsorption } \\
\text { capacity (mg/g) }\end{array}$ & $\underset{\left(\mathrm{mg} / \mathrm{dm}^{3}\right)}{\operatorname{Max}} C_{0}$ & Reference \\
\hline Biomass-based activated carbon by $\mathrm{FeCl}_{3}$ activation & $259.2 \mathrm{mg} / \mathrm{g}$ & $450 \mathrm{mg} / \mathrm{dm}^{3}$ & [7] \\
\hline Propylene diamine basic activated carbons & $182.0 \mathrm{mg} / \mathrm{g}$ & $700 \mathrm{mg} / \mathrm{dm}^{3}$ & [8] \\
\hline Recyclable magnetite-loaded palm shell-waste based activated carbon & $163.3 \mathrm{mg} / \mathrm{g}$ & -- & [9] \\
\hline Activated carbon prepared from dross licorice by ultrasonic & $82.90 \mathrm{mg} / \mathrm{g}$ & $200 \mathrm{mg} / \mathrm{dm}^{3}$ & [10] \\
\hline Steam activated carbon from lantana camara stem & $19.84 \mathrm{mg} / \mathrm{g}$ & $200 \mathrm{mg} / \mathrm{dm}^{3}$ & [11] \\
\hline Activated lignin-chitosan composite extrudates & $36.25 \mathrm{mg} / \mathrm{g}$ & $82 \mathrm{mg} / \mathrm{dm}^{3}$ & This study \\
\hline Hydrophobic activated carbons & $34.70 \mathrm{mg} / \mathrm{g}$ & $700 \mathrm{mg} / \mathrm{dm}^{3}$ & [8] \\
\hline
\end{tabular}

3

4

5

6

7

8

9

10 Table 2: Calculated parameters for kinetic models for the adsorption of MB on ALiCE at different initial

11 MB concentrations.

\begin{tabular}{cccccccc}
\hline & & \multicolumn{3}{c}{ Pseudo-first-order } & \multicolumn{3}{c}{ Pseudo-second-order } \\
\hline $\boldsymbol{C}_{\mathbf{0}}$ & $q_{\exp }$ & $q_{\mathrm{e}}$ & $k_{1}$ & $R^{2}$ & $q_{\mathrm{e}}$ & $k_{2} \times 10^{2}$ & $R^{2}$ \\
\hline $\mathbf{1 0 . 1 5}$ & 4.601 & 4.266 & 0.016 & 0.978 & 4.448 & 0.570 & 0.995 \\
$\mathbf{1 9 . 3 7}$ & 8.137 & 7.377 & 0.009 & 0.978 & 7.817 & 0.170 & 0.993 \\
$\mathbf{3 3 . 7 7}$ & 14.08 & 12.81 & 0.007 & 0.976 & 13.89 & 0.060 & 0.993 \\
$\mathbf{4 0 . 0 2}$ & 16.13 & 14.58 & 0.004 & 0.979 & 16.36 & 0.030 & 0.993 \\
$\mathbf{5 9 . 3 7}$ & 22.98 & 20.70 & 0.003 & 0.977 & 23.43 & 0.020 & 0.994 \\
$\mathbf{8 2 . 0 1}$ & 27.90 & 26.44 & 0.001 & 0.978 & 29.04 & 0.010 & 0.980 \\
\hline
\end{tabular}

$12 \quad\left(C_{0}: \mathrm{mg} / \mathrm{L} ; q_{\mathrm{e}}: \mathrm{mg} / \mathrm{g} ; k_{1}: 1 / \mathrm{min} ; k_{2}: \mathrm{g} / \mathrm{mg} \min \right)$.

13

14

15 
1 Table 3: Intraparticle rate parameters and diffusion coefficients of MB adsorption onto ALiCE at 2 different MB initial concentrations.

\begin{tabular}{ccll}
\hline$C_{0}$ & $\begin{array}{c}\text { Intraparticle } \\
\text { diffusion, } k_{\text {id }}\end{array}$ & $\begin{array}{l}\text { Film diffusion, } D_{1} \\
\times 10^{10}\end{array}$ & $\begin{array}{l}\text { Pore diffusion, } D_{2} \\
\times 10^{11}\end{array}$ \\
\hline 10.15 & 0.264 & 1.766 & 8.371 \\
19.37 & 0.477 & 1.420 & 5.028 \\
33.77 & 0.720 & 1.116 & 4.220 \\
40.02 & 0.727 & 0.712 & 1.936 \\
59.37 & 1.046 & 0.653 & 1.498 \\
82.01 & 1.171 & 0.581 & 1.031 \\
\hline
\end{tabular}

3 (kid $: \mathrm{mg} / \mathrm{g} \cdot \mathrm{min}^{0.5} ; D_{1}$ and $\left.D_{2}: \mathrm{cm}^{2} / \mathrm{s}\right)$.

4

5

6

7

8 Table 4: Isotherm model parameters for adsorption of MB onto ALiCE.

\begin{tabular}{lllll}
\hline Model & Parameters & & \\
\hline Langmuir isotherm & $\boldsymbol{q}_{\max }$ & $\boldsymbol{b}$ & $\boldsymbol{R}^{\mathbf{2}}$ & \\
\cline { 2 - 5 } & 36.25 & 0.121 & 0.997 & \\
\hline Freundlich isotherm & $\boldsymbol{K}_{\mathbf{F}}$ & $\boldsymbol{n}$ & $\boldsymbol{R}^{\mathbf{2}}$ & \\
\cline { 2 - 5 } & 7.024 & 2.472 & 0.978 & \\
\hline Redlich-Peterson isotherm & $\boldsymbol{K}_{\mathbf{R}}$ & $\boldsymbol{a}_{\mathbf{R}}$ & $\boldsymbol{\beta}$ & $\boldsymbol{R}^{\mathbf{2}}$ \\
\cline { 2 - 5 } & 4.626 & 0.146 & 0.965 & 0.996 \\
\hline Sips isotherm & $\boldsymbol{q}_{\max }$ & $\boldsymbol{K s}_{\mathrm{s}}$ & $\boldsymbol{n s}_{\mathrm{s}}$ & $\boldsymbol{R}^{\mathbf{2}}$ \\
\cline { 2 - 5 } & 38.75 & 0.128 & 0.898 & 0.996 \\
\hline
\end{tabular}

9 


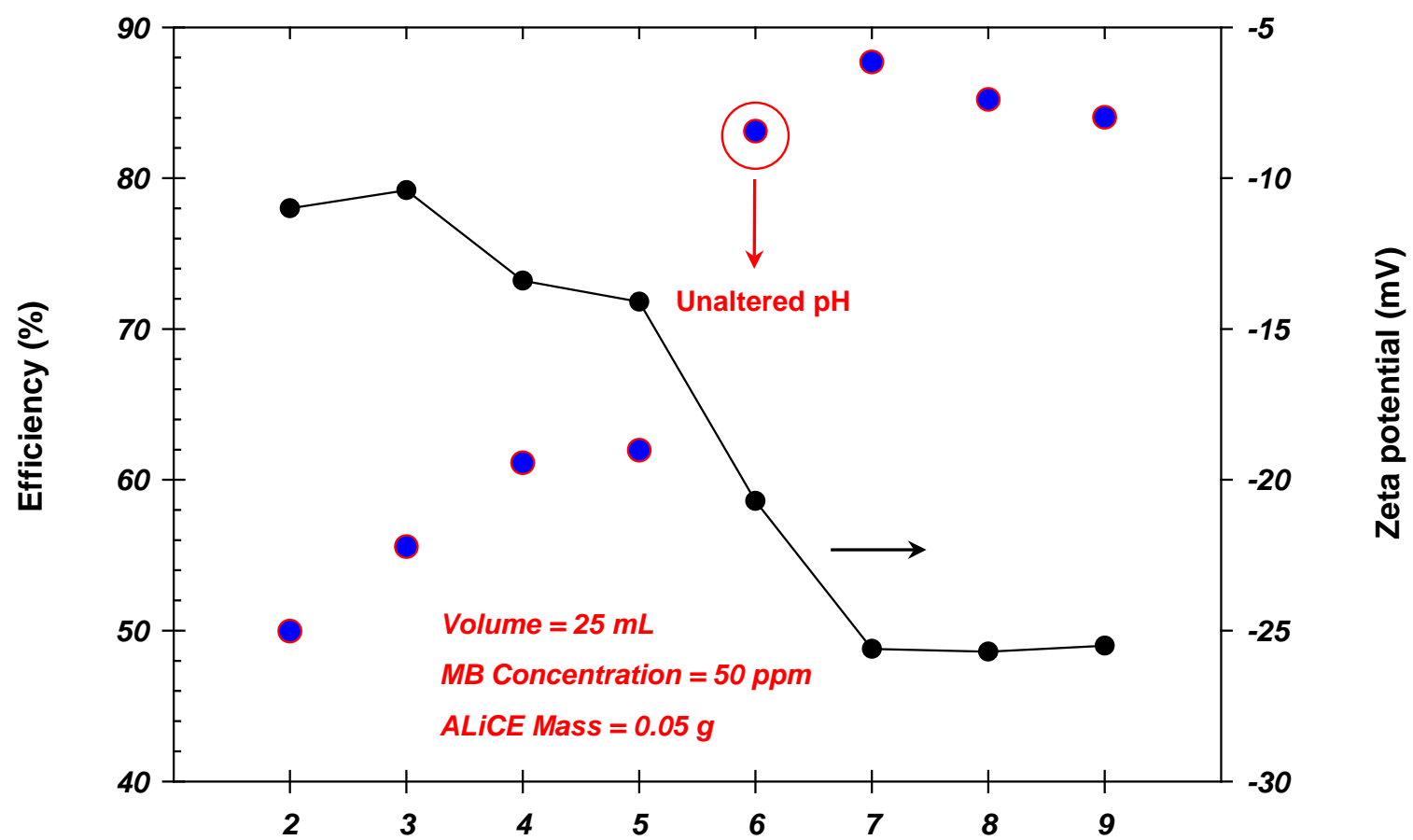

$\mathrm{pH}$ of MB solution

1

3 Figure 1: Effect of the $\mathrm{pH}$ values on the adsorption of MB onto ALiCE.

4

5

6 


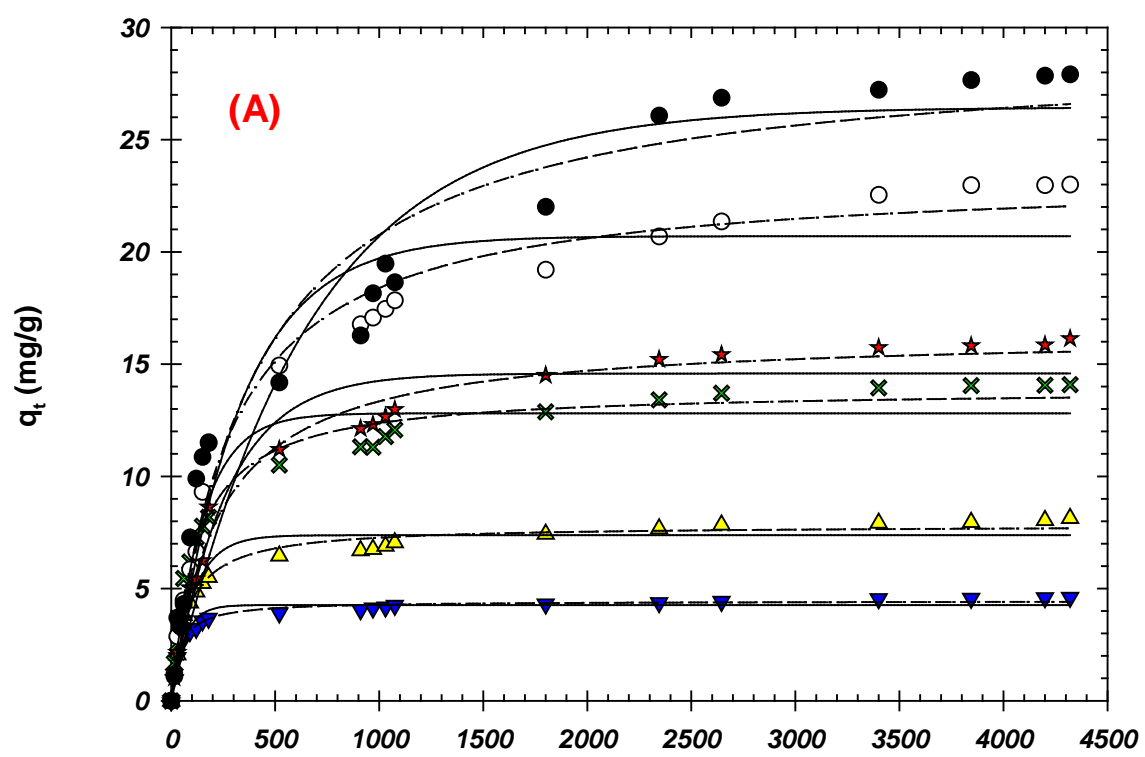

Contact time (min)

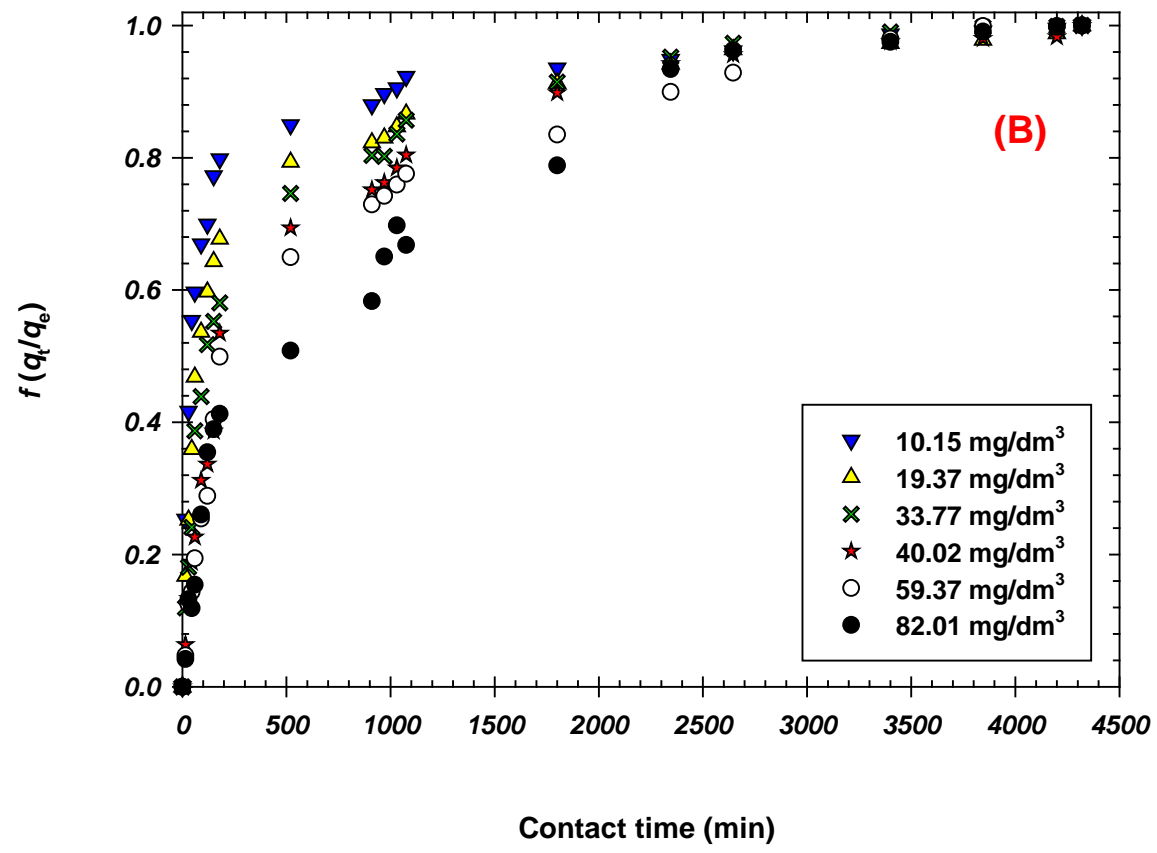

3 Figure 2: (A) Pseudo-first-order kinetics and pseudo-second-order kinetic models for the 4 adsorption of MB onto ALiCE, and (B) Plots of the fractional uptake $f\left(q_{t} / q_{\mathrm{e}}\right)$ for MB adsorption 5 onto ALiCE at different concentrations.

6 


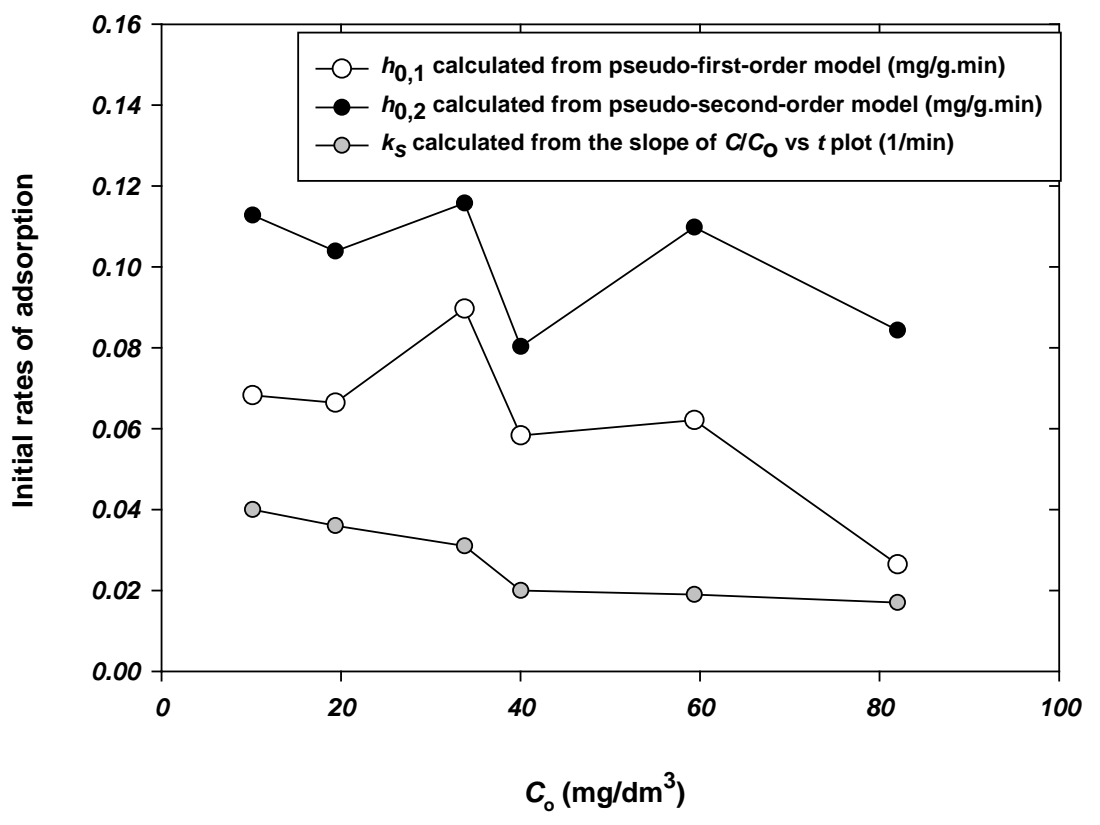

2 Figure 3: The discrepancy of the initial rates of adsorption at different initial MB 3 concentrations.

4

5

6 

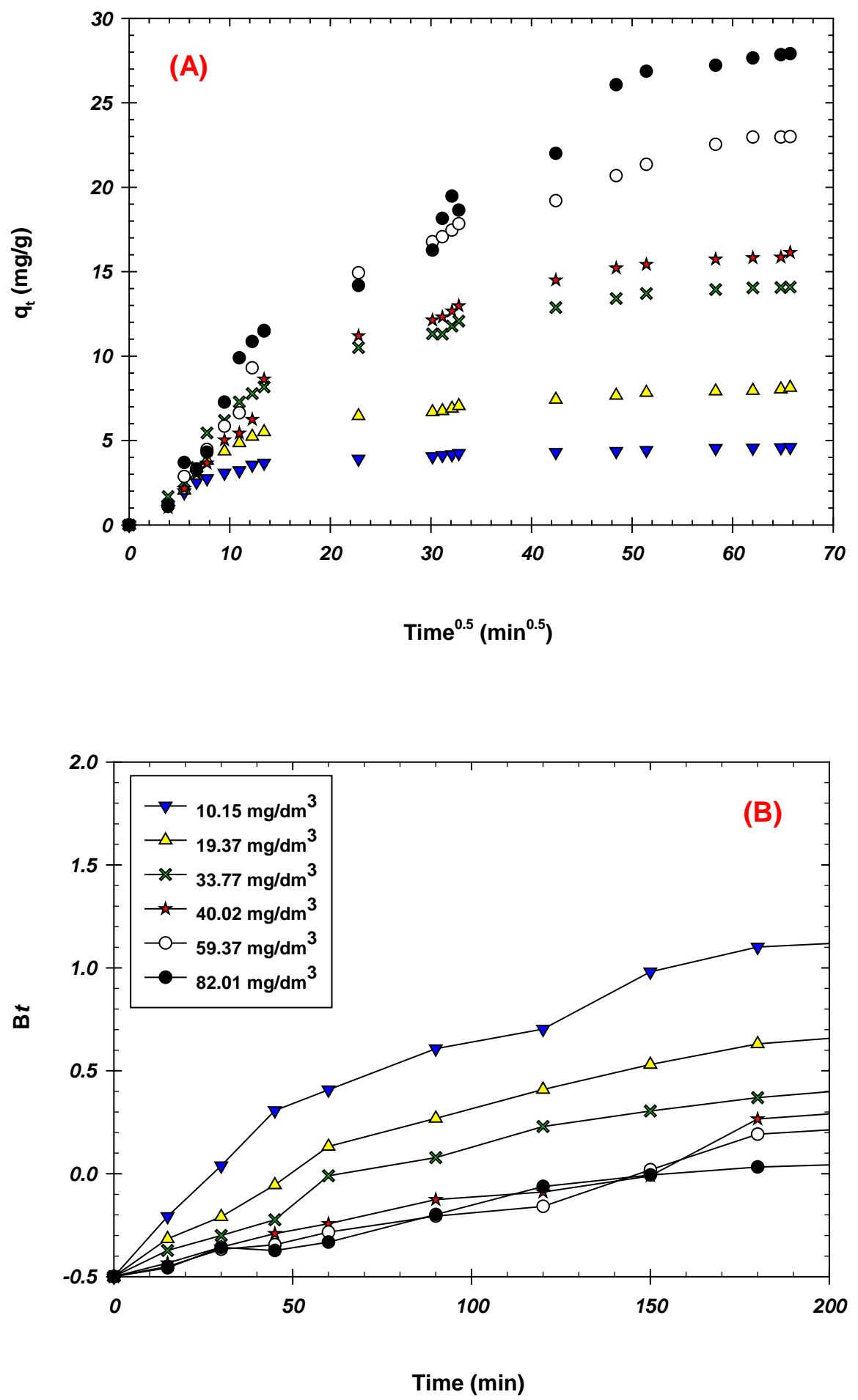

3

4 Figure 4: (A) Intraparticle diffusion model for the adsorption of MB onto ALiCE at various 5 initial MB concentrations and (B) Boyd plots for MB adsorption onto ALiCE at different initial $6 \quad$ MB concentrations. 

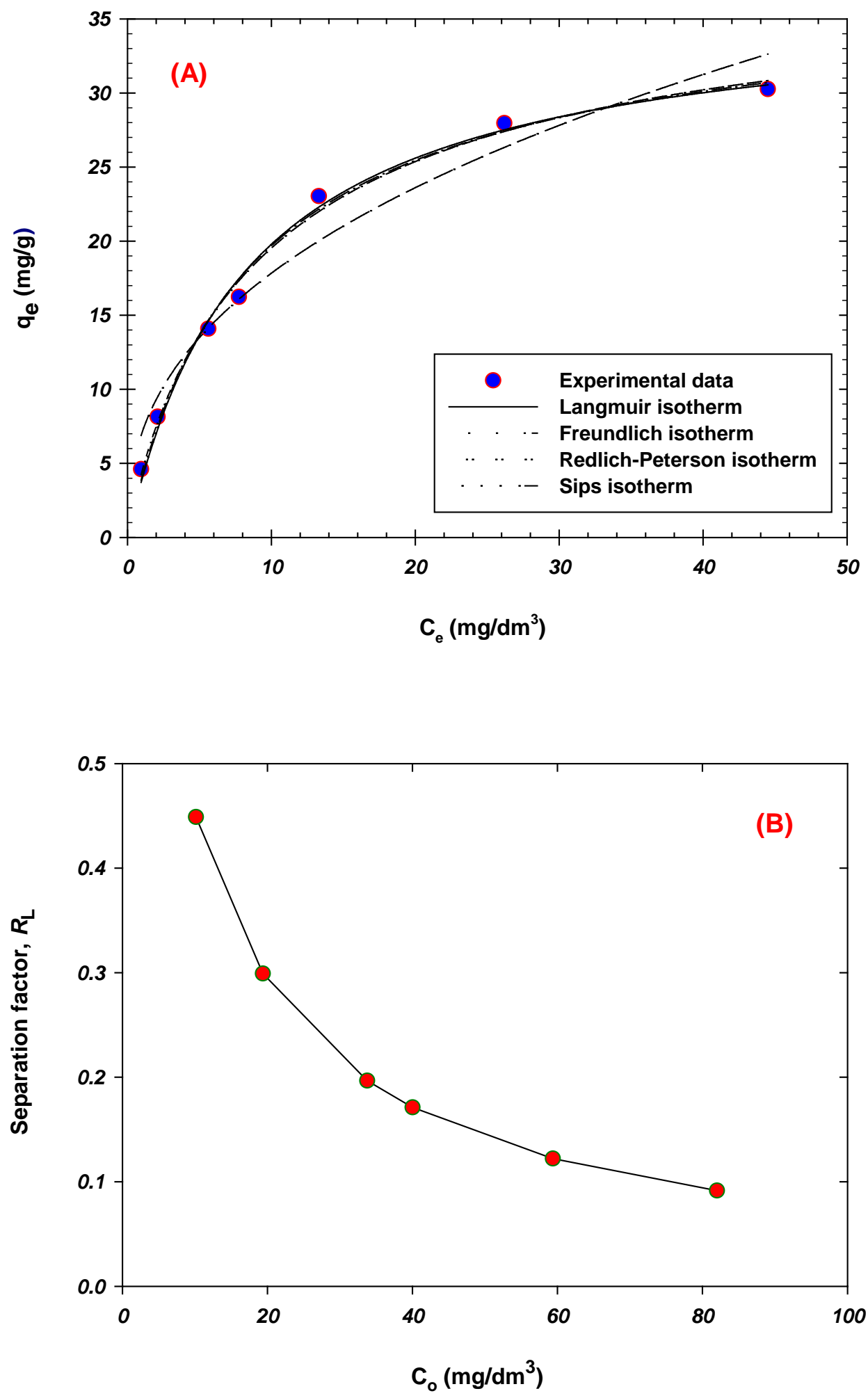

3 Figure 5: (A) Isotherm plots for MB adsorption onto ALiCE and (B) Separation factor, $R_{\mathrm{L}}$, for 4 the adsorption of MB onto ALiCE. 


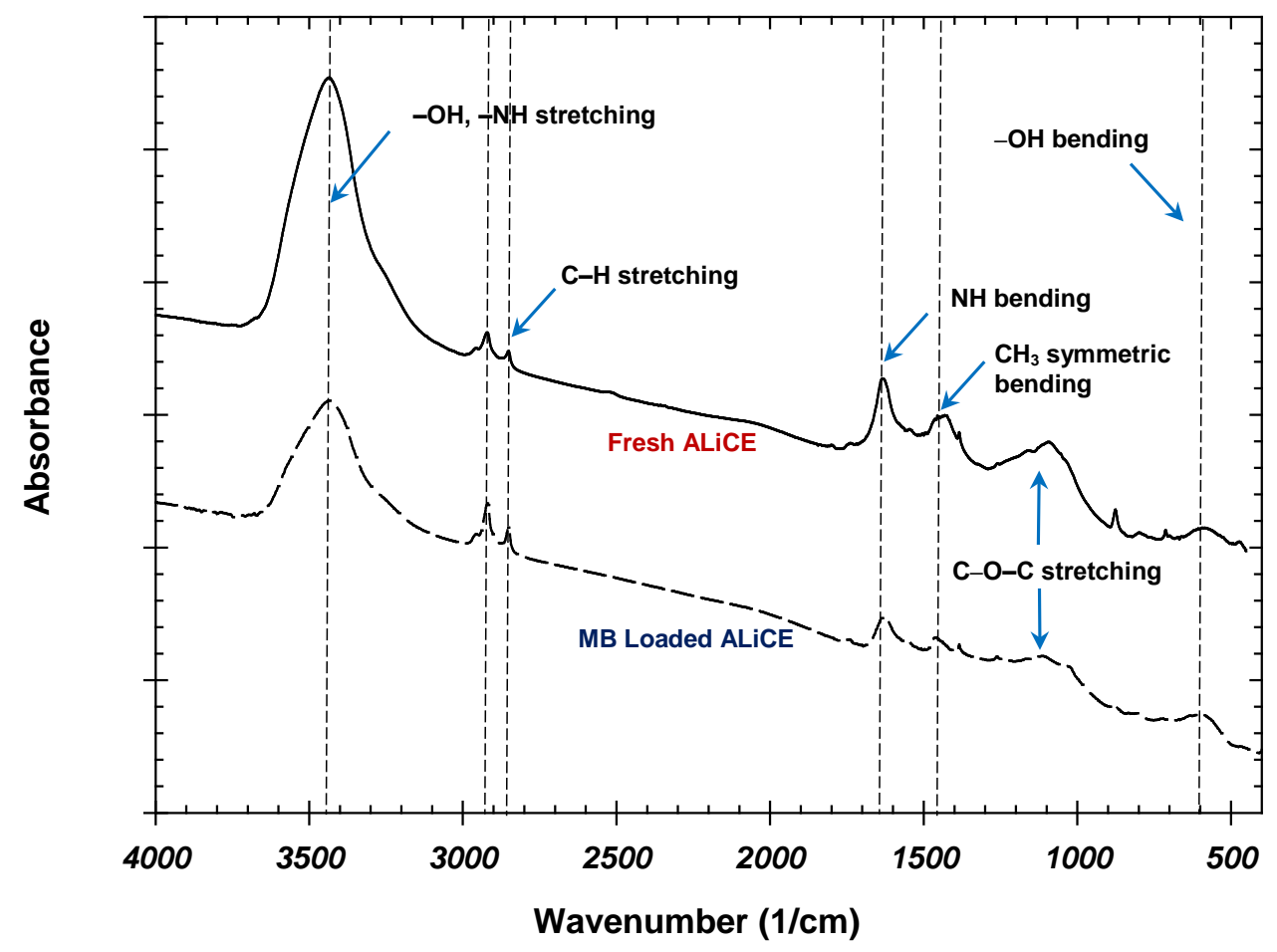

1

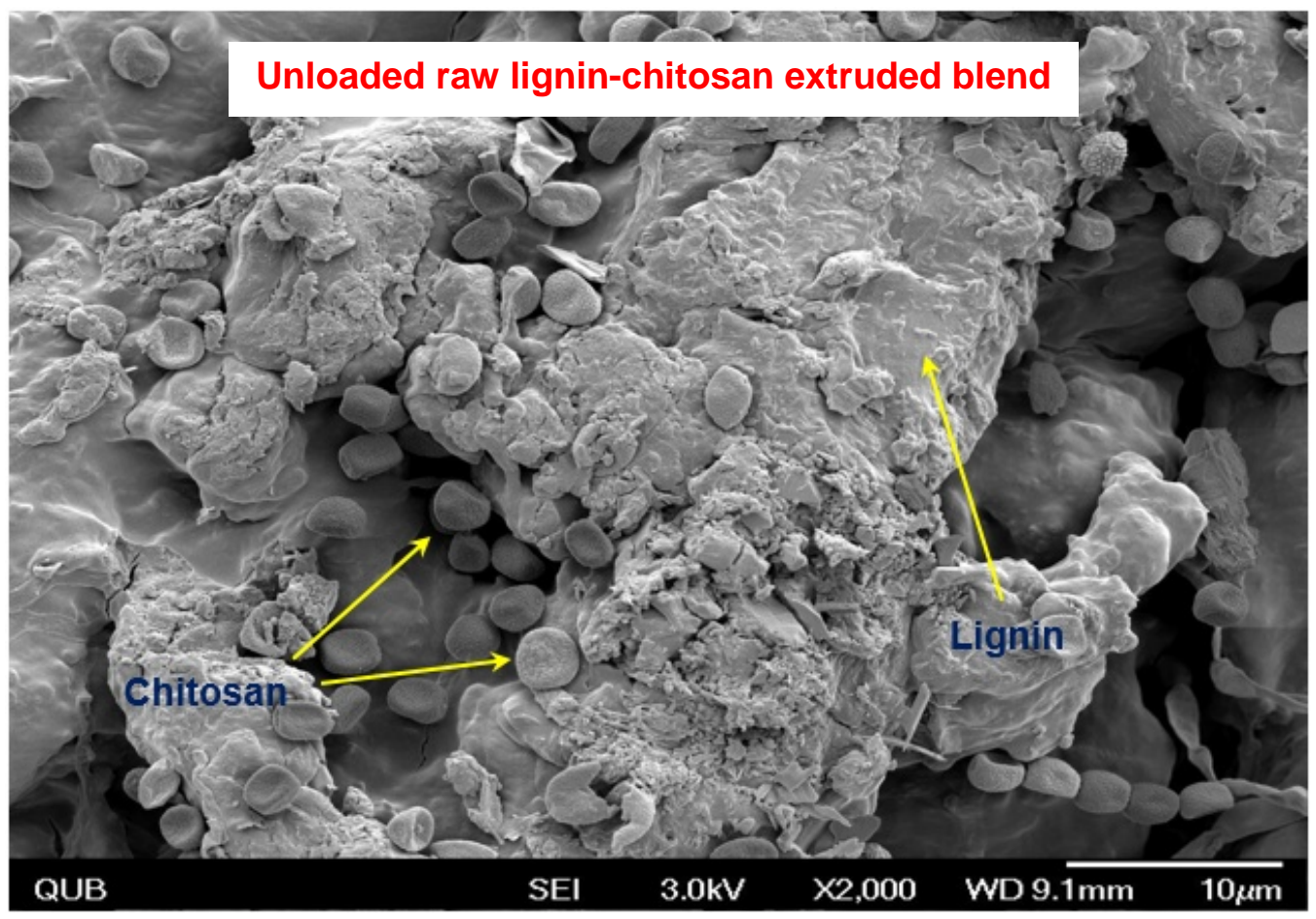



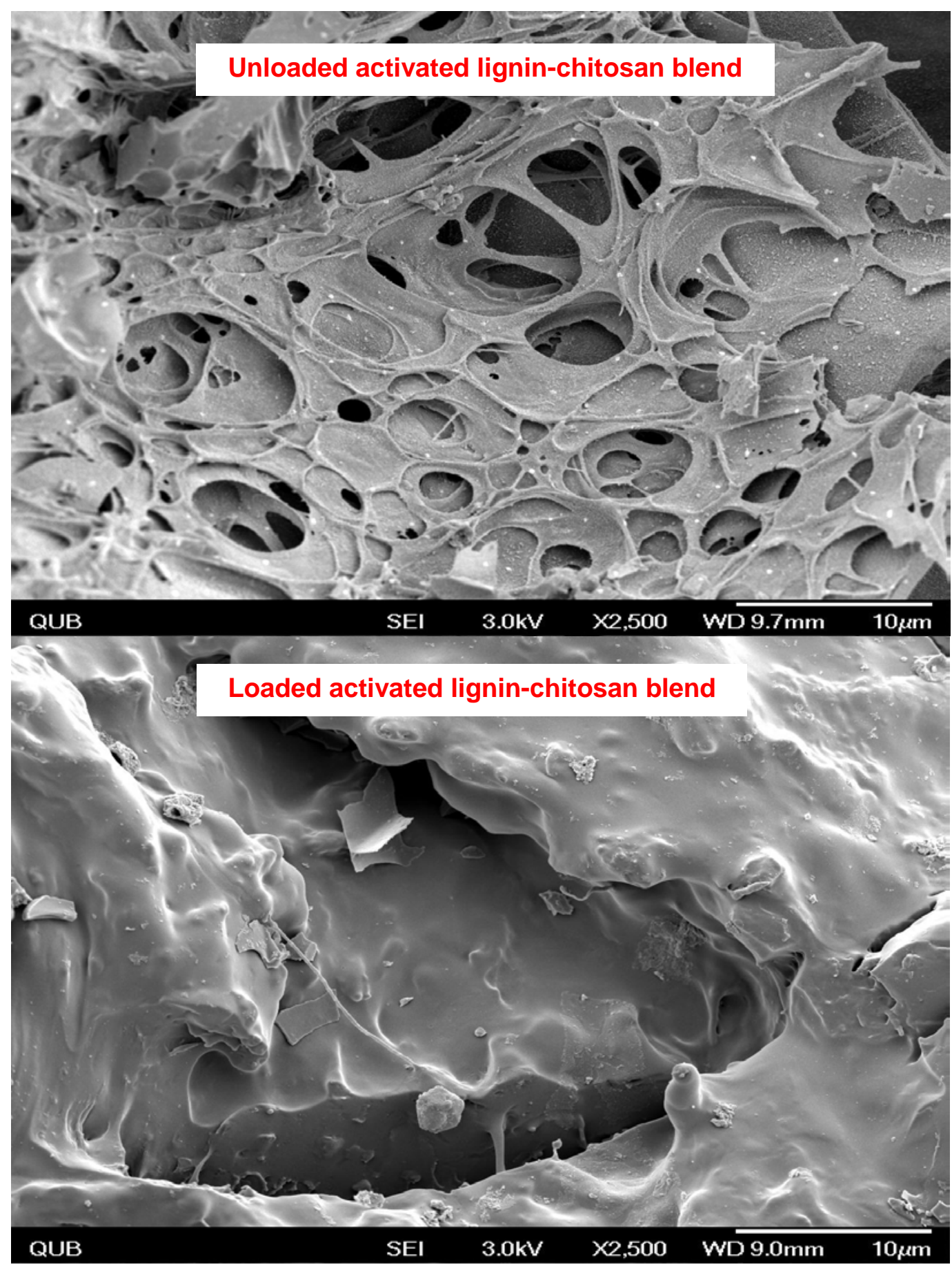


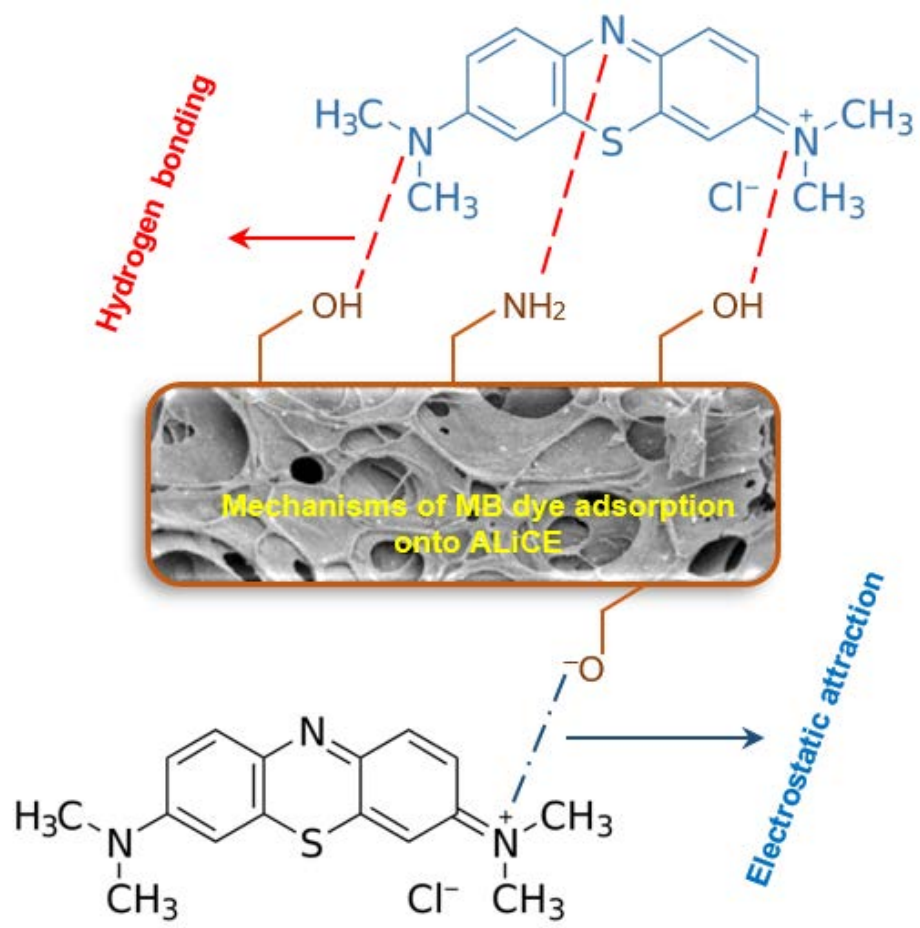

2 Figure 6: FT-IR spectra, SEM images for ALiCE adsorbent before and after MB adsorption

3 and proposed adsorption mechanisms.

4

5

6

7

8

9

10

11

12

13 